\title{
"Aqui tem que ter atividade mesmo, nesse trabalho tem que ser ligado": Riscos, implicações e estratégias de defesa para a saúde de coletores de lixo domiciliar
}

Celiana Pereira de Souza ${ }^{1}$, Anísio José da Silva Araújo, Paulo César Zambroni-de-Souza

Universidade Federal da Paraíba, João Pessoa, Paraíba, Brasil

\section{Palavras-chave:}

psicodinâmica do trabalho;

risco ocupacional;

coletores de lixo domiciliar.

\section{Resumo}

Este artigo investiga os diferentes riscos, suas consequências para a saúde e as estratégias de defesa desenvolvidas pelos coletores de lixo domiciliar de uma cidade do Nordeste brasileiro. Utilizamos como referencial teórico a Psicodinâmica do trabalho, especialmente a reflexão sobre riscos, perigo e estratégias defensivas. Realizamos entrevistas semiestruturadas com 13 trabalhadores do sexo masculino. Para a análise dos dados, optamos pela análise de conteúdo temática. Evidenciou-se que a intensa exposição a riscos traz consequências à saúde desses trabalhadores e grande parte delas decorre das condições de trabalho e do acondicionamento inadequado do lixo por parte da população. A relação desses trabalhadores com os riscos é mediada pela utilização de estratégias defensivas que, apesar de atenuarem o sofrimento, pouco contribuem para transformar positivamente as situações de trabalho.

Here you really have to be active, in this work you have to be alert": Risks, implications, and defense strategies for the health of garbage collectors

\section{Keywords:}

psychodynamics of work;

occupational risk;

garbage collectors.

\begin{abstract}
This article investigates the different risks, their health consequences, and the defense strategies developed by the garbage collectors of a city in the northeast of Brazil fordealing with this situation. We use as our theoretical reference the Psychodynamics of Work, especially the reflection on risks, danger, and defensive strategies. We conducted semistructured interviews with 13 male workers. For data analysis, we opted for thematic content analysis. It has been shown that the intense exposure to risks has consequences for the health of these workers, most of which result from poor working conditions and inadequate packaging of garbage by the population. The relation of these workers to suchrisks is mediated by the use of defensive strategies that, although theymitigate suffering, do little to positively transform their work situations.
\end{abstract}

Aquí hay que tener actividad sí, a este trabajo hay que estar atento: Riegos, implicaciones y estrategias de defensa para la salud de basureros

\section{Resumen}

Este artículo investiga los diferentes riesgos, sus consecuencias para la salud y las estrategias de defensa desarrolladas por los basureros de una ciudad del nordeste brasileño, para lidiar con esa situación. Utilizamos como referencial teórico la Psicodinámica del Trabajo, especialmente la reflexión sobre riesgos, peligro y estrategias defensivas. Realizamos entrevistas semi estructuradas con 13 trabajadores de sexo masculino. Para el análisis de los datos, optamos por el análisis de contenido temático. Se evidenció que la intensa exposición a riesgos trae consecuencias a la salud de estos trabajadores y gran parte de ellas derivan de las condiciones de trabajo y del acondicionamiento inadecuado de labasura por parte de la población. La relación de estos trabajadores con los riesgos es mediada por la utilización de estrategias defensivas que, a pesar de atenuar el sufrimiento, poco contribuyen a transformar positivamente las situaciones de trabajo.

\footnotetext{
Endereço para correspondência:

Rua Teresina, no 96, casa, bairro: Três Irmãs, 58.423-050, Campina Grande, PB-Brasil. E-mail: celianapereirasouza@gmail.com

Como citar este artigo:

Souza, C. P., Araújo, A. J. S., \& Zambroni-de-Souza, P. C. (2019).“Aqui tem que ter atividade mesmo, nesse trabalho tem que ser ligado”: Riscos, implicações e estratégias de defesa para a saúde de coletores de lixo domiciliar. Revista Psicologia: Organizações e Trabalho, 19(1), 555-563. doi: 10.17652/rpot/2019.1.15307
} 
Este artigo tem por objetivo caracterizar os riscos presentes na atividade de coleta de lixo domiciliar, suas implicações para a saúde e as estratégias de defesa elaboradas pelos coletores de lixo domiciliar (Classificação Brasileira de Ocupações -CBO 5142-05), de uma cidade do Nordeste brasileiro, para lidar com essa condição de trabalho. A fundamentação teórica baseia-se na Psicodinâmica do trabalho, abordagem que procura refletir, entre outras questões, o modo comoos trabalhadores percebem e vivenciam os riscos típicos de sua atividade de trabalho e o que fazem parase defender, objetiva e subjetivamente (Dejours, 2012).

$\mathrm{Na}$ cidade onde ocorreu a pesquisa, os coletores de lixo domiciliar estão vinculados a um órgão da Prefeitura Municipal. Os varredores de rua (CBO 5142-15), encarregados da varrição das ruas, e os trabalhadores de serviços de limpeza e conservação de áreas públicas (CBO 5142-25), responsáveis pela poda das árvores, pinturas de meio-fio, entre outras atividades, são contratados por meio de concurso público (regime efetivo) e os coletores de lixo domiciliar, responsáveis pela coleta do lixo domiciliar, são contratados por uma única empresa terceirizada. Embora estejam todos na mesma categoria da CBO (5142: Trabalhadores nos serviços de coleta de resíduos, de limpeza e conservação de áreas públicas) e que possamos supor que aqueles funcionários concursados estejam sujeitos a variados riscos em sua atividade, não se discutirá esse quadro neste artigo, que tem como foco ao que estão sujeitos os coletores de lixo domiciliar. Conforme apontam estudos em diversos setores, como Araújo (2001) na petroquímica, Echternachte Castro (2017) no setor elétrico, Silva e Muniz (2011) no meio hospitalar, entre outros, a terceirização tende a deixar os trabalhadores muito mais sujeitos a adoecimentos e acidentes do que aqueles que não estão nessa condição. Esse quadro agrava os riscos a que estão sujeitos os trabalhadores que participaram da presente pesquisa, cuja atividade já é considerada como de risco em grau máximo (Smidt \& Vendruscolo, 2006).

A atividade de coleta de lixo domiciliar, que focalizamos nesse artigo, é essencial para o funcionamento adequado das cidades, em que a produção de lixo aumenta a cada dia. Além disso, ela está intrinsecamente vinculada à promoção de saúde pública, uma vez quea retirada do lixo impede a propagação dos mais diversos tipos de males, como proliferação de vetores de diferentes doenças, poluição da natureza, prejuízo à estética da cidade, entre outros. Todavia, o objeto lixo, fonte de riscos, como apresentaremos no decorrer deste artigo, pode, se não manipulado adequadamente, incidir negativamente sobre a saúde e a integridade física dos trabalhadores.

As condições de trabalho na coleta de lixo domiciliar são semeIhantes entre as regiões brasileiras e se caracterizam basicamente pela falta de tecnologia adequada e por trabalhadores recolhendo toneladas de lixo diariamente, correndo atrás dos caminhões compactadores, conforme depreende-se dos trabalhos de Lazzari e Reis (2011), Vasconcelos, Lima, Abreu e Coutinho Filho (2008); de Velloso, Santos e Anjos (1997) e deste artigo. Os estudos mostram aspectos semelhantes aos encontrados nesta pesquisa em Estados como São Paulo, Mato Grosso do Sul, Rio de Janeiro, mostrando os efeitos do neoliberalismo globalizado, procurando padronizar os modos de produzir em diferentes lugares, precarizando-os ao limite (Stiglitz, 2002). Embora imprescindível, quase sempre é uma atividade desvalorizada, razão pela qual não atrai a atenção necessária no tocante a diminuição dos riscos e suas consequências para a saúde dos trabalhadores.

Diversos estudos abordam os riscos físicos, químicos, biológicos, ergonômicos e sociais dessa atividade e suas consequências para a saúde dos trabalhadores, que podem levar a tétano, raiva e HIV (Anjos \& Ferreira 2000; Lazzari \& Reis, 2011; Santos, 2008; Souza, 2009). Entretanto, há nessas investigações um aspecto que não tem sido explorado suficientemente: a maneira como os trabaIhadores vivenciam os riscos e as estratégias de defesa elaboradas para enfrentá-los, com vistas a atenuar o sofrimento, permitindo, assim, trabalhar com segurança.

\section{Psicodinâmica do trabalho e riscos no trabalho}

Os riscos no trabalho, em maior ou menor grau, estão presentes nas múltiplas atividades laborais, de forma que trabalhar é sinônimo de embate e confronto com os riscos a todo instante (Dejours, 2012; Molinier, 2013; Nouroudine, 2004). No entanto, pensamos ser necessário deixar claro que isso não isenta as organizações dos riscos a que submetem os trabalhadores com a precarização e a falta de preocupação com sua saúde e segurança. Se o trabalho com lixo traz riscos inerentes à atividade, estes são potencializados com as condições e a organização do trabalho a que estão sujeitos. Em relação à definição, Rouquayrol e Goldbaum (1999) consideram o risco ocupacionalcomo a probabilidade de que aconteça determinado evento danoso à saúde, podendo manifestar seus efeitos em curto, médio ou longo prazo considerando as condições predisponentes do suposto acontecimento.

O enfrentamento para a buscar o controle dos riscos é algo que deve estar verdadeira e constantemente na pauta das organizações. Certamente, a busca desse controle não significa que seja possível suprimi-los, já que os riscos estão presentes em qualquer atividade (Nourouddine, 2004), mas tentar evitá-los é condição indispensável à saúde do trabalhador. Dessa forma, o medo de acidentar-se, de mutilar-se ou de adquirir doença profissional, de não corresponder ao que exige a tarefa ou suas responsabilidades, despertam verdadeiros conflitos intrapsíquicos. Esses impasses, comuns e intrínsecos à tarefa, atingem diretamente o corpo físico e o funcionamento psíquico (Dejours, 2012).

Assim, ao trabalhar, a ação dos homens não se limita apenas à produção, pois enquanto trabalham, eles também buscam proteção contra o sofrimento e os riscos presentes na atividade. Desse modo, o fazem principalmente por intermédio de estratégias de defesa, elaboradas no decurso do trabalho. Ainda que o sofrimento se revele singular, dessas estratégias participa todo o coletivo de trabalho que se dedica em modificar de maneira simbólica a postura subjetiva diante dos riscos, tornando possível o trabalhar (Dejours, 2011; 2012).

Molinier (2013) defende que as estratégias defensivas têm como finalidade intervir na percepção dos riscos, removendo-os da consciência. Entretanto, modificar a percepção não elimina o risco objetivo, desestabilizador em potencial. Essas estratégias voltamse intencionalmente para a construção de um universo simbólico comum e adquirem consistência na medida em que são organizadas de acordo com crenças, condutas e atitudes. O objetivo é reduzir ao máximo possível as implicações derivadas da percepção da realidade geradora de angústia. Nesse sentido, nega-se a realidade para insensibilizar-se diante do sofrimento produzido por ela, o que pode gerar no sujeito uma exposição ainda maior aos efeitos deletérios presentes no trabalho, na medida em que não mais se reconhece conscientemente os riscos ali presentes.

Dejours (2017) destaca que essas estratégias, além de elaboradas pelo coletivo, colaboram de modo essencial e até mesmo contribuem para fundar e estabelecer o coletivo de trabalho. É por partilharem desse entendimento e de determinadas condutas frente ao risco e ao perigo que é possível reconhecer-se enquanto membros de um coletivo e estabelecer relações assentadas na 
solidariedade e na confiança. É um sistema complexo de defesas, cujo papel é o de conter o medo, possibilitando a realização da atividade. Todos devem adotá-las, do veterano ao novato, caso contrário, compromete-se a eficácia da estratégia defensiva.

\section{Riscos na atividade de coleta de lixo domiciliar e repercussões para} a saúde dos trabalhadores

A atividade de coleta de lixo domiciliar é marcada pela presença de uma variedade de riscos, que podem gerar graves problemas para a saúde dos trabalhadores. Normalmente, os riscos estão categorizados em seis grupos: físicos, químicos, biológicos, ergonômicos, mecânicos e sociais, cada qual podendo ocasionar determinadas consequências negativas para a saúde física e psíquica do trabalhador (Anjos \& Ferreira, 2000; Lazzari, 2009; Pedrosa, Gomes, Mafra, Alburque \& Pelentir, 2010).

Os riscos físicos são decorrentes de máquinas, equipamentos, condições físicas e características do local de trabalho. Compreendem ruídos, vibrações, calor, frio, umidade, radiações ionizantes e não ionizantes. Suas principais consequências são cansaço, irritação, dores de cabeça, diminuição da audição, aumento da pressão arterial, problemas no aparelho digestivo, taquicardia, risco de infarto, dores nos membros e coluna, doença do movimento, artrite, lesões ósseas e dos tecidos moles, aumento de pulsação, prostração, choque e fadiga térmicos, perturbações das funções digestivas, hipertensão, fenômenos vasculares periféricos, queimaduras, doenças do aparelho respiratório, circulatório e de pele, quedas, alterações celulares, câncer, fadiga, problemas visuais, e lesões nos olhos, pele e órgãos (Dos Santos, 2007; Santos, 2008; Smidt \& Vendruscolo, 2006; Souza, 2009).

Os riscos químicos são derivados de compostos, substâncias ou produtos que penetram no organismo pela via respiratória. Compreendem poeiras minerais, vegetais, alcalinas, fumos metálicos, névoa, gases e vapores. As principais implicações para a saúde são: doença pulmonar obstrutiva crônica, enfisema pulmonar, intoxicação, irritação das vias aéreas superiores, dores de cabeça, náuseas, sonolência, convulsões, coma, morte, ação depressiva sobre o sistema nervoso, danos aos diversos órgãos e ao sistema formador do sangue (Dos Santos, 2007; Smidt \& Vendruscolo, 2006; Souza, 2009).

Os riscos biológicos procedem de agentes capazes de causar doenças devido à contaminação. Abrangem: vírus, bactérias e protozoários que são fontes de doenças infectocontagiosas, como hepatite, cólera, amebíase, aids, tétano, etc.; fungos e bacilos, causadores de infecções variadas externas, como as dermatites, e internas, como as doenças pulmonares, além de parasitas desencadeadores de infecções cutâneas ou sistêmicas e contagiosas (Dos Santos, 2007; Lazzari \& Reis, 2011; Santos, 2008; Smidt \& Vendruscolo, 2006; Souza, 2009; Velloso et al., 1997).

Os riscos ergonômicos derivam: do esforço físico decorrente do levantamento e transporte manual decargas, de exigências de posturas inadequadas, que causam cansaço, dores musculares, fraquezas, hipertensão arterial, diabetes, úlcera, doenças nervosas, acidentes e problemas da coluna vertebral; de ritmos excessivos e do regime de trabalho em turnos e noturno, da monotonia e repetitividade, da jornada prolongada, do controle rígido de produtividade que acarreta alterações do sono, da libido e da vida social, com reflexos na saúde e no comportamento, além de doenças nervosas, do aparelho digestivo (gastrite, úlcera, etc.), inclusive tensão, ansiedade, medo e comportamentos estereotipados (Dos Santos, 2007; Santos, 2008; Souza, 2009; Velloso et al., 1997).
Os riscos mecânicos compreendem quedas, atropelamentos, esmagamentos pelo compactador de lixo, fraturas, etc. Um dos principais riscos advém do subir e descer do caminhão. É nessa atividade que podem acontecer quedas e batidas no estribo do veículo. $\mathrm{O}$ fato de estar constantemente em velocidade e o mau cheiro exalado pelo lixo que se encontra no compactador podem causar tonturas que levam a quedas. Os atropelamentos decorrem dos veículos que estão circulando nas ruas. Além disso, existe o risco de mordidas de animais soltos nas ruas (Dias, Matos, Braga, Magossi, Diniz, \& Antonio, 2015; Santos, 2008; Velloso et al., 1997).

Os riscos sociais, por sua vez, decorrem da forma que o trabalho é organizado pelas empresas que, em função do regime de funcionamento em turnos alternados, pode afetar as relações sociais com a família e amigos eefeitos do descontrole no ciclo sono-vigília (Seligmann-Silva, 2011). A carga excessiva do trabalho, as jornadas longas, a falta de treinamento e de condições adequadas de trabalho também são fontes de riscos para os profissionais de coleta de lixo domiciliar (Dias, Matos, Braga et al, 2015; Lazzari, 2011; Santos, 2008). Como destaca Oliveira (2016), o trabalho com material degradado (nesse caso, o lixo) coloca as pessoas que o realizam em situação de maior desvalorização social, naturalizando que essas pessoas possam ser expostas a riscos sem respeito à sua saúde e segurança. No caso brasileiro, em que a escravidão fez parte do processo de formação da nação e está presente muitas vezes na mentalidade daqueles que administram as organizações (Vasconcellos, 2002), a negação do lugar de sujeito aos trabalhadores que realizam esse tipo de atividade agrava o quadro.

\section{Método}

O presente estudo foi realizado entre fevereiro e maio de 2017 na empresa responsável pela coleta de lixo domiciliar de uma cidade de médio porte do Nordeste brasileiro. Obedeceu a um delineamento não experimental, de natureza qualitativa, de caráter descritivo e construído a partir de relatos dos profissionais de coleta de lixo domiciliar.

\section{Participantes}

Participaram deste estudo 13 coletores de lixo domiciliar, dos quais oito são trabalhadores diurnos e cinco são noturnos. Todos são do sexo masculino, com idades variando entre 25 a 51 anos (M $=32$; $\mathrm{DP}=6,94)$. A condição para participar do estudo foi determinada pelo interesse e disposição de cada profissional, que, voluntariamente, registrou sua assinatura em um Termo de Consentimento Livre e Esclarecido, que incluía a autorização para a gravação das entrevistas. Ressalta-se que a participação levou em consideração os aspectos éticos envolvendo investigação sobre seres humanos, conforme resolução no 510/2016 do Conselho Nacional de Saúde. Este estudo foi submetido e aprovado por Comitê de Ética em Pesquisa.

\section{Instrumentos}

Para a realização deste estudo, optamos por dois instrumentos, sendo o primeiro um questionário sociodemográfico e o segundo uma entrevista semiestruturada, cujo roteiro foi construído a partir das categorias teóricas desta pesquisa. Procurou-se contemplar as seguintes temáticas: histórico profissional; atividade de trabalho de coleta domiciliar, o que implicou investigar como é o dia de trabalho, que tipos de imprevistos podem ocorrer, que táticas são desenvolvidas (individual e coletivamente) para lidar com esses imprevistos; quais são as condições de trabalho a que estão submetidos, quais os riscos estão expostos e como lidam com eles; 
como se apresentam as relações intersubjetivas, com a hierarquia, com os pares e com os usuários do serviço; se são percebidos ou não reconhecidos; o que os faz sofrer e ter prazer no trabalho; e, por fim, quais as implicações psíquicas e sociais associadas a essa atividade de trabalho.

\section{Procedimentos de coleta de dados e cuidados éticos}

Primeiramente contatou-se a gerência da empresa para apresentação da proposta de estudo. A aceitação ocorreu sem entraves, sendo exigido apenas o aval de um comitê de ética em pesquisa. Cumpridas as exigências, ficou autorizado o início da pesquisa. Em seguida, a gerência intermediou o contato como encarregado em razão de sua proximidade com os coletores. Este, favoreceu, de maneira substantiva, o elo entre a pesquisadora e os trabalhadores. Respeitando a dinâmica da empresa, em dia e horário previamente acordados, foi apresentada a proposta de estudo aos trabalhadores e feito o convite para participar. Diante da concordância dos presentes, foram agendadas as entrevistas individuais, que aconteceram na empresa, sempre no final do expediente, para os trabalhadores diurnos, e antes dele, para os noturnos. Com o consentimento dos trabalhadores, as 13 entrevistas foram gravadas e transcritas na íntegra.

\section{Procedimento de análise de dados}

O tratamento dos dados foi conduzido por meio da análise de conteúdo temático na perspectiva proposta por Laville e Dionne (1999). Para esses autores, o princípio da análise de conteúdo é marcado pela revelação da estrutura e dos elementos que compõem o conteúdo, dessa forma, são delineadas suas múltiplas características e extraídas sua significação, ou seja, um esforço de compreensão dos significados da fala no seu contexto, a partir de inferências relativas à sua temática. A definição das categorias analíticas foi norteada pelo modelo misto, embasadas no referencial teórico adotado e nos conhecimentos teórico-práticos dos pesquisadores. A partir dos elementos produzidos em campo, foram construídas oito categorias de análise, sendo riscos, condições de saúde e estratégias de defesa as abordadas neste artigo.

\section{Resultados e discussão}

1. "Risco nesse trabalho é o que não falta, tem de todo tipo, físico, químico, biológico, etc.". Riscos na atividade de coleta de lixo domiciliar e condições de saúde dos trabalhadores.

A existência dos riscos é própria de toda atividade de trabalho (Dejours, 1992). Portanto, falar da atividade pressupõe considerar a presença do risco, o que não significa ignorar as diferenças relativas à quantidade e à variedade de riscos, e ao seu potencial de se transformar em acidentes e adoecimento entre as diferentes atividades de trabalho. De acordo com Nouroudine (2004), "a realização do trabalho, no sentido de atividade humana, pelo engajamento corporal, cognitivo e mental que ela supõe por parte dos atores, é de ponta a ponta atravessada pelo risco" (p.44). Diante da constatação da presença do risco em toda situação de trabalho (embora em graus variados), é preciso, além de identificá-los, entender como os trabalhadores (no caso em análise, os coletores de lixo) os percebem e os vivenciam em seu dia a dia.

Não é sem razão que a atividade de coleta de lixo domiciliar é considerada insalubre em grau máximo (Smidt \& Vendruscolo, 2006). No presente estudo, os coletores de lixo domiciliar reconheceram diferentes tipos de riscos a que estão expostos, pois, ao serem questionados sobre esse tema, todos destacaram a presença dos riscos de contaminação por agentes físicos e químicos, mas principalmente biológicos e de acidentes, já que são os mais rotineiros. Além destes, apontaram também riscos ergonômicos e mecânicos.

A maioria dos riscos físicos decorre da própria natureza da atividade: um trabalho ininterrupto, ${ }^{2}$ que acontece forçosamente sob condições de sol ou chuva. $\mathrm{O}$ ambiente de trabalho é a rua, condição que deixa os coletores sujeitos às particularidades do meio, especialmente às oscilações climáticas. Durante a jornada de trabalho, estão expostos a altos índices de radiação solar, que podem acarretar desde queimaduras, rugas, manchas na pele, até câncer; o compressor do carro coletor, por sua vez, permanece ligado continuamente, emitindo ruídos que, com o passar do tempo, podem vir a acarretar algum tipo de problema auditivo, como a perda auditiva induzida pelo ruído (PAIR). Em pesquisa junto a motoristas de caminhões de lixo, Flaig (2004) encontrou considerável ocorrência de PAIR. Além disso, o ruído pode acarretar também alterações não auditivas, como "irritabilidade, cefaleia, insônia, alterações circulatórias, alteração de visão e alterações gastrointestinais" (Ministério da Saúde, 2006, p. 20). Assim, ruídos, vibrações, radiações solares, calor, frio e umidade são características próprias dessa atividade de trabalho (Santos, 2008; Souza, 2009; Smidt \& Vendruscolo, 2006).

Conforme ressalta Dejours (2012), os riscos não são controlados inteiramente e há, inclusive, aqueles que escapam de serem administrados, visto que a realidade do trabalho de facto não permite que seja diferente. Essas peculiaridades inerentes à atividade de coleta de lixo domiciliar e potencialmente danosas à danosas à saúde são os riscos sob os quais a possibilidade de controle é reduzida. Os efeitos negativos produzidos por essa realidade atingem diretamente o corpo, mas podem abarcar o funcionamento psíquico dos coletores, como mostra a fala seguinte "essa quentura [...] que é quente demais e isso incomoda muito, irrita e estressa" (Participante 8).

Percebe-seque os riscos químicos são potencializados pela ausência da coleta seletiva do lixo que, no caso brasileiro, está longe de ser generalizada. Em geral, o lixo domiciliar contém restos químicos nocivos à saúde e o contato com essas substâncias pode ter efeitos deletérios para a saúde, como relatou um deles: "Dor de cabeça o cabra sente, por causa do cheiro forte do lixo, por causa da catinga do lixo [...] náuseas, aquela vontade de vomitar [...] às vezes nem fica no serviço por isso" (Participante 3). Embora os participantes do estudo não tenham dado muita ênfase às implicações dos riscos físicos e químicos, talvez pela enorme força que os outros riscos tenham em seu dia a dia de trabalho, não é difícil constatar a sua presença e as suas possíveis implicações para a saúde (Santos, 2008, Smidt \& Vendruscolo, 2006; Souza, 2009).

Diante dos riscos presentes na atividade de coleta de lixo domiciliar, os mais sentidos e declarados pelos trabalhadores neste estudo foram os riscos biológicos, seguidos dos riscos de acidentes por objetos perfurocortantes e atropelamentos. Os coletores de lixo estão expostos ao contato inevitável com bactérias, vírus, fungos e outros microrganismos presentes no lixo e que são detentores de grande poder de transmissibilidade (Lazzari \& Reis, 2011). Assim, expôs um trabalhador: "Eu peguei uma bactéria nas duas mãos, fiquei seis meses pra ficar bom" (Participante 4). Essa fala ilustra a consciência do perigo decorrente do contato como lixo, cuja contaminação levou, nesse caso, cerca de seis meses até a cura.

Percebe-se o quanto é custoso para esses trabalhadores estar continuamente tomado pelo medo de se contaminar e de contrair

\footnotetext{
É um trabalho dinâmico, com trechos e horários a serem cumpridos, e os carros coletores são os mesmos para a coleta diária e noturna. Assim, não é possível parar a coleta em decorrência de fatores físicos, pois comprometeria o turno seguinte.
} 
alguma enfermidade em decorrência do manuseio cotidiano do lixo, como relatou um deles:

\begin{abstract}
"A gente enfrenta riscos de doenças sim, tem bactérias e a gente tem medo, pega uma bactéria, sai uns caroços aí, essa doença avança em cima de você e você nem sabe que tá com ela, é muito arriscado e ainda esse mau cheiro do carro. Esse mau cheiro do carro fica na gente, é muito arriscado pra gente que sempre acha no lixo vidro, seringas, injeção que podem estar contaminados e de vez em quando furam a gente." (Participante 9)
\end{abstract}

Para proteger-se desse tipo de riscos é preciso apelar para o uso de equipamentos de proteção individual (EPI), especialmente quando a situação de trabalho não possibilita o uso de equipamentos de proteção coletiva (EPC), solução desejável do ponto de vista da segurança e da saúde no trabalho. No caso em análise, o que constatamos é que os EPIs não cumprem o seu papel de proteção pelas razões expostas a seguir por alguns participantes: "As luvas que são de pano e a farda que é de um tecido quente não são lá essas coisas não" (Participante 10); "Pessoal aí só usa de pano aí é mesmo que nada [...] quando tá chovendo é muito fácil de pegar bactéria" (Participante 3). Embora saibamos que a oferta de EPIs seja insuficiente para garantir a segurança, entendemos que a falta ou a inadequação deles expõe os trabalhadores a situações de riscos aos quais não precisariam se submeter se as condições de trabalho, assim como sua organização, fossem satisfatórias.

É alto o risco de contaminação ocasionado por objetos perfurocortantes, como vidros, seringas, restos de cerâmica, espinhos de plantas, latas e pregos enferrujados, entre outros. Esses objetos são capazes de perfurar ou mesmo romper as luvas utilizadas pelos coletores esão responsáveis por lesionar a pele, ocasionando a entrada de patógenos, presentes no lixo, na corrente sanguínea, como relatado a seguir:

"Ah vírus, ah! Já vi muitos com a pele necrosada porque pega essas coisas aí, já vi colegas meus que adquiriram bactérias e que temos certeza que foi do lixo também, e foram bactérias pesadas e grande viu, de pegar assim na pele e quando elas pegam na pele elas não ficam só no pedacinho não, sabe, ela sai comendo, sai comendo tudo." (Participante 5)

Outras maneiras de contaminação foram detectadas na pesquisa. O município onde ocorreu esse estudo passava por uma crise hídrica, com a água quase sempre considerada imprópria para o consumo humano. Em dias mais quentes, a água que os coletores transportam para consumo próprio não é suficiente, o que faz eles recorrem aos moradores, que, em muitos casos, fornecem uma água imprópria, responsável por diarreias e gastrenterite de origem infecciosa, como relata a seguir um participante da pesquisa: "Realmente quase todo mundo teve diarreia aqui, mas a gente achou que o motivo era a água sabe, porque aí no meio da rua a gente toma todo tipo de água" (Participante 11). Mas essa não é a única causa dessas doenças, como afirma outro trabalhador: "Sempre temos diarreias porque não tem como ter um controle assim, a gente pega em muitas seboseiras e leva as mãos à boca" (Participante 8).

Dejours (2012) adverte que quando a atividade de trabalho envolve riscos que ameaçam a integridade física dos trabalhadores, seja por trabalhar em ambientes insalubres, seja por manipular substâncias capazes de provocar um desfecho fatídico, o medo do acidente, da mutilação e da doença profissional acende conflitos intrapsíquicos. Na fala seguinte, o trabalhador exprime o desconforto por ter contraído uma bactéria no trabalho, o constrangimento de não mais escutar corretamente e o medo de perder inteiramente a audição.

"Uma bactéria que pegou aqui na audição. É muito ruim por que às vezes inflama, às vezes dói, o médico falou pra mim que foi uma bactéria que eu peguei que tá perturbando. Tá comendo, roendo umas áreas que tem aqui, ela não é tal como dizem aí maligna, benigna ela é. Faz uns três anos. [...] Já perdi muito de minha audição, posso ficar surdo por causa disso, você tá percebendo que já não lhe escuto direito, sei que você está falando muito alto, mesmo assim tenho dificuldade de escutar direito, por isso peço pra você sempre repetir." (Participante 9)

De acordo com Seligmann-Silva (2010), um trabalhador que sofre um acidente de trabalho perde, além de suas defesas psicológicas, o sentimento de pertencimento a um grupo ou comunidade profissional. A rejeição que esse trabalhador experimenta pode acarretar sérios riscos à saúde. Nessas circunstâncias, depressão e outros transtornos mentais de fundo psíquico ou mesmo psicossomático podem ser manifestados.

Os coletores de lixo erguem e transportam cotidianamente sacos pesados de lixo. A má distribuição do peso por depósitos ou mesmo sacos e sacolas ocasiona desde pequenos incômodos até lesões como entorses, lombalgias, epicondilite, esporão de calcâneo, hérnia de disco e muitas outras (Campos, Rubinho, \& Pereira, 2016). O trabalhador acometido por dores decorrentes da atividade de trabalho convoca seus pares para dividir o esforço despendido no levantamento e transporte de peso, buscando minimizar o impacto negativo na saúde. 0 relato a seguir demonstra essa situação:

"As dores musculares que sinto tão relacionadas sim ao trabalho porque é um trabalho que você [...] se movimenta muito sabe, e principalmente as dores que você sente no joelho e no tornozelo, se você pula de cima do carro, é força, se você vai subir no carro, é força novamente, é um trabalho que é que abaixando por isso a gente sente muitas dores." (Participante 11)

Esse quadro de sofrimento e adoecimento musculoesquelético poderia ser minimizado com o uso de tecnologias já disponíveis em outros países, como França e Alemanha, e mesmo em alguns lugares do Brasil, em que os recipientes que contêm o lixo são acoplados e despejados diretamente no caminhão, sem que o coletor de lixo domiciliar precise subir e descer tantas vezes.

A grande ocorrência de quedas, fraturas e escoriações é típica desse tipo de atividade, evidenciada neste e também em outros estudos. Esses fatores de risco, entre outros, sinalizam a necessidade de atenção especial à saúde desses trabalhadores (Pinho \& Neves, 2010). Muitas vezes, na tentativa de alcançar a velocidade imposta pelo motorista do caminhão, os coletores acabam correndo muito rápido e tropeçando nos obstáculos físicos, como os relatos a seguir: "Além desse corte, já sofri quedas no trabalho, no decorrer do trabalho mesmo têm calçadas altas aí a gente tá sempre correndo quando vê a gente tem tropeçado e caído feio, fica todo arranhado" (Participante 7); "Eu mesmo eu já sofri um, aqui ó. Isso aqui é uma cicatriz de quatro pontos" (Participante 5).

Entretanto, esses não são os únicos fatores responsáveis pelas quedas, fraturas, arranhões e machucados sofridos pelos coletores de lixo. Atitudes indevidas da população, como jogar substâncias líquidas e gordurosas dentro do lixo, também têm um papel desencadeante nesses tipos de acidentes. $O$ derramamento de óleos, graxas e banhas no estribo do carro compactador proporciona uma superfície escorregadia capaz de fazer o trabalhador deslizar, cair e se ferir, como exposto a seguir. 
"Fica escorregadio porque ali você pega todo tipo de coisa. Às vezes pega uma coisa com óleo e quando vai jogar lá no carro cai um pouco na plataforma ali e quando você vai subir às vezes tá escorregando e você cai termina se machucando né?" (Participante 11)

Os acidentes de trânsito, como os atropelamentos, fazem parte do cotidiano de quem trabalha nessa atividade (Santos 2008; Santos, Lima, Murta \& Mota, 2009; Smidt \& Vendruscolo, 2006; Vasconcelos, Lima, Camarotto, Abreu, \& Cotinho Filho, 2008). Entre os diversos fatores de risco, alguns em especial reforçam e colaboram para a manutenção e o aumento desses acontecimentos nefastos à saúde desses profissionais. Em ruas de mão dupla, os sacos ou reservatórios de lixo estão distribuídos e concentrados nos dois lados da via pública de modo que os coletores precisam se arriscar entre os veículos para poder transportá-los até o carro compactador. Com a guarnição incompleta que força o aumento do ritmo da atividade acrescido do desrespeito dos condutores de veículos motorizados, os riscos de colisão são ainda mais potencializados, o que pode provocar desde contusões, ferimentos graves, mutilação e até mesmo a morte desses profissionais, como relatado a seguir:

"É um trabalho perigoso mesmo, principalmente pra quem trabalha na contramão, eu mesmo sou um que trabalha na contramão, têm horas que eu pego o lixo assim e venho aí tem que parar, se não o carro que vem, é carro, é moto, é bicicleta. [...] No ano retrasado aconteceu comigo, o carro tava trabalhando com três agentes, a gente tava forçando pra dar conta, ai do jeito que eu vinha com os sacos de lixo na pressa, a moto aqui, ia torando eu no meio." (Participante3)

Para inibir a ocorrência de situações que podem provocar acidentes graves, os coletores procuram redobrar a atenção no decorrer do trabalho, tomando para si a responsabilidade de escaparem das surpresas do real. Assim, assumem uma responsabilidade que, no mínimo, deveria ser compartilhada com a empresa. Apesar disso, são conscientes de que os esforços para diminuir o risco são insuficientes. Não obstante, precisam ser muito cautelosos para não serem responsabilizados, como ressaltam Velloso, Valadares e Santos (2010). No entanto, essa atividade, ao mesmo tempo em que exige muita precaução, vigilância, porque os riscos são múltiplos, tem características que dificultam o exercício dessa atenção. Nesse sentido, a correria e a pressão por produção comprometem negativamente a atenção desses trabalhadores, como descreve o participante a seguir: "A gente trabalha pra frente aí não tá constantemente olhando atrás, a gente até olha pra atrás, mas sempre vem um carro ou uma moto ligeiro [...] quem trabalha na contramão tem que prestar bastante atenção, né?" (Participante 6).

"O que precisa mesmo é nós ter cuidado, olhar direitinho, mas o problema é que a gente passa muito rápido, pega os sacos ligeiro e não vai ter tempo de olhar, passa assim e pega o 'moi', se tiver 10 sacos nós pega os 10, ai não tem como pra olhar de um em um, aí acaba que nós sempre se machuca mesmo." (Participante 2)

Além de todo o esforço físico exigido, os trabalhadores também precisam permanecer constantemente atentos ao que ocorre ao seu redor. Desse modo, manter vigilância sobre tantos aspectos significa uma carga mental elevada e uma razão de cansaço. Assim, toda situação de trabalho vai gerar diferentes cargas para o sujeito e em graus variados. O trabalho nunca é apenas braçal, ele é também mental e tem repercussões para o trabalhador (Dejours, Abdoucheli, \& Jayet, 2011).
2. "Aí como eu faço para me proteger? Cuidado, eu tomo sempre muito cuidado, um cuidado dobrado": Estratégias de defesa e proteção à saúde

Para sustentar-se psiquicamente diante dos constrangimentos e efeitos deletérios do trabalho, os trabalhadores lançam mão de estratégias defensivas cuja finalidade é eufemizar o sofrimento psíquico. Trata-se, portanto, de atenuar a percepção da realidade para que seja possível suportá-la. Via de regra, para conseguir esse feito, é necessário que os trabalhadores sejam agentes ativos, implicados. Não obstante, essa é uma operação estritamente mental, não modifica em nada a realidade patologizante (Dejours, Abdoucheli, \& Jayet, 2011).

Para defender-se do sofrimento e do adoecimento físico e/ ou mental que vivenciam no trabalho, os trabalhadores em geral utilizam estratégias defensivas individuais e/ou coletivas. Todavia, sempre que as estratégias individuais se encontram esgotadas ou então já não se apresentam eficazes como meios de defesa contra a nocividade das situações insalubres e deletérias do trabalho, existe ainda a possibilidade de construir estratégias coletivas que são organizadas e compartilhadas entre os participantes de um determinado meio profissional (Dejours, 1992; Dejours \& Abdoucheli, 1994).

Como apontado anteriormente, nessa atividade, os coletores estão expostos a uma série de riscos, constrangimentos e vulnerabilidades que podem acarretar danos à saúde e ao bem-estar. Assim, para fazer frente a essa situação e diminuir o máximo possível a possibilidade de ser alvo das adversidades próprias da atividade, eles se empenham em realizar cuidadosamente certas manobras a fim de resguardarem sua integridade. Porém, essa missão não é nada simples. A fala seguinte faz menção às dificuldades encontradas para preservar-se: "O certo é pegar nas orelhas da bolsa e não pegar na bolsa mesmo [...] mas só que tem muitas vezes que eles botam o lixo, aí fica estufada [...] não tem nem onde você pegar" (Participante 13). A mesma dificuldade é mencionada pelo participante 4 , que deixa claro, assim como o participante 13 , a importância do gesto utilizando-se das orelhas, mas impossibilitado pela inadequação dos instrumentos utilizados pela população para acondicionar o lixo:

"Rapaz pra proteger, pra proteger mesmo só Jesus, porque têm horas que não dá para você ver não, e você só se protege mesmo quando você vê, porque eles botam nas bolsas aí fecha as bolsas pretas [...] aí o certo é pegar nas orelhas da bolsa e não pegar na bolsa mesmo não, porque evita muita coisa isso, mas só que tem muitas vezes que eles botam o lixo aí fica estufada assim a bolsa aí não tem nem onde você pegar, quando você pega assim nela pra tentar jogar ela escorrega aí você vai pegar de novo aí é onde você se fura muitas vezes." (Participante 4)

Essas estratégias são utilizadas pelos coletores que são conscientes que pegar as sacolas de lixo pelas alças (orelhas) é o recomendável, pois evita o contato direto com o lixo. Contudo, isso nem sempre é possível porque o excesso de lixo favorece o encolhimento delas, bem como dificulta o arremesso no carro de coleta. As sacolas de cores mais escuras também se revelam uma armadilha, pois não permitem que eles enxerguem o seu conteúdo. Muitas vezes, o peso acarreta o rompimento das alças e isso obriga o coletor a pegar diretamente nas sacolas e até mesmo no próprio lixo quando elas rasgam, tornando maior o risco de acidentes e de contaminação pelo contato direto.

A prática de uma higienização sistemática constitui uma estratégia de enfrentamento para eliminação dos possíveis agentes transmissores de doenças que porventura tenham se alojado na farda ou mesmo no corpo do coletor durante a jornada de trabalho. 
Com esse cuidado, acreditam diminuir os problemas de pele como sarna, micoses, além de remover outros seres vivos indesejados como vermes, bactérias e vírus que podem penetrar no organismo por alguma porta de entrada e/ou mesmo quando levam as mãos à boca, causando danos irreparáveis à saúde. A respeito disso, esclarece um participante: "Pra me proteger é chegar em casa e tomar um banho bem tomado, passar uma bucha no corpo, um sabão de coco, um sabão neutro, sabe, aí você vai se protegendo aos poucos." (Participante 5)

Por ser uma das principais vias de condução e transmissão de microrganismos em geral, as mãos precisam ser lavadas sempre que possível. Quando não é possível, o uso do álcool em gel pode desinfetá-las, conforme esclarecem: "Eu sempre compro, quando eu faço minha feirinha, eu sempre coloco um tubinho de álcool em gel, ai quando eu vou almoçar ou comer alguma coisa eu limpo com ele e pronto" (Participante1); "Alguns aqui no trabalho usam o álcool em gel na hora que vai almoçar na hora que vão eles passam nas mãos" (Participante 5). Essa última fala revela que alguns coletores têm esse cuidado, o que constitui certamente uma estratégia de prevenção com efeitos positivos. Não obstante, pode se revelar insuficiente diante da variedade e agressividade dos fatores de risco. Nessa situação, há uma clara ausência de responsabilização da empresa empregadora, pois, as luvas são inadequadas, como dito anteriormente, de tal forma a deixar que os próprios trabalhadores tenham que criar estratégias para combater os riscos presentes na atividade.

Com a experiência adquirida no trabalho eles sabem que, com muito peso, precisam agir de modo a não comprometer ainda mais a coluna. Quando os sacos de lixo estão mais leves eles pegam somente na parte superior, mas se estiverem demasiadamente pesados, precisam pegar em cima e embaixo, como relatado na fala seguinte:

"Porque a gente já conhece né o trecho, já sabe onde o lixo é pesado e não é, quando é muito pesado e a gente sabe, pesado assim que dá pra um pegar só, é pegar em cima e embaixo, você nunca pode pegar um lixo pesado e puxar com as duas mãos que vai travar sua coluna, disso a gente já sabe." (Participante 4)

Embora essa estratégia possa representar uma quantidade menor de danos à coluna, ela atua favorecendo um contato maior entre trabalhador e o lixo, o que aumenta o risco de contágio pelas substâncias nele contidas.

Três coletores nunca adoeceram, se acidentaram ou se contaminaram. Acreditam que isso não ocorreu porque são protegidos por Deus, que os envolve com uma segunda pele, mais robusta e impermeável, que bloqueia a possibilidade dessas ocorrências: "Graças a Deus eu nunca adoeci aqui não, eu tenho saúde sobrando, nunca tive nada, graças a Deus, nada" (Participante 2); "Graças a Deus até agora eu ainda não vi nem vivi nada grave, só se arranha, se arranha, mas bate a poeira e vamo embora de novo (risos) é o jeito" (Participante 11); "Nunca peguei nada disso não, de bactéria essas coisas, graças a Deus, também não me furei, mas cortes sim" (Participante 12). Seja efetiva ou não, essa justificativa para o não adoecimento representa uma operação psíquica que certamente auxilia na convivência com os riscos.

Apesar das estratégias desenvolvidas e praticadas pelos trabalhadores, é necessário realçar que elas não eliminam os riscos e muito menos modificam as situações reais de trabalho. Segundo Dejours, Abdoucheli e Jayet (1994), as estratégias elaboradas diante decertas situações de trabalho, apesar de terem um papel importante em razão de possibilitar a manutenção de um equilíbrio psíquico pela via da eufemização das situações causadoras de sofrimento, não transformam a realidade geradora de constrangimentos, apenas favorecem a adaptação do trabalhador ao sofrimento. No caso dos trabalhadores que participaram desta pesquisa, utilizam-se, por exemplo, das estratégias defensivas coletivas de ajudarem-se uns aos outros quando o saco está demasiadamente pesado, de todos estarem atentos aos veículos que vêm de trás do caminhão. Ao lado delas, utilizam-se de estratégias individuais de defesa usando álcool gel nas mãos ou estando especialmente atento ao trânsito, no caso de quem trabalha na contramão dos veículos que circulam pela via. Assim, diante de tantos riscos, utilizam-se dessas e outras estratégias coletivas, que são "toda uma série de processos psíquicos que vão contribuir para lutar contra a ameaça de descompensação" (Dejours \& Gernet, 2012, p. 21).

\section{Considerações finais}

Neste estudo, objetivamos evidenciar os riscos advindos da atividade de coleta de lixo domiciliar e suas consequências para a saúde, além das estratégias defensivas que os trabalhadores utilizam para lidar com o perigo e o medo inerente a essa situação de trabalho. Essa atividade é circundada por riscos diversos, assim como acontece com outras atividades semelhantes. Contudo, um fator que sobressai é a forma como os riscos são normalmente encarados.

Constata-se uma atenção insuficiente no enfrentamento para a busca do controle dos riscos por parte da empresa, especialmente se considerarmos o volume e a variedade dos riscos presentes nessa atividade de trabalho. Defendemos, com base em Porto e Freitas (1997), que uma forma efetiva de gerenciamento de riscos deve partir do princípio de que a tecnologia, o meio ambiente e o risco são resultantes de processos sociais. Assim, devem ser considerados os pontos de vista das populações que habitam o entorno dessas indústrias, dos trabalhadores e das instituições públicas e privadas que representam os interesses sociais, políticos e econômicos da sociedade.

Mesmo reconhecendo a dificuldade de extingui-los totalmente, faz-se necessário empenhar-se no sentido de gerenciá-los da melhor forma, trazendo melhorias nas condições e na organização do trabalho. A responsabilidade de conceber meios que colaborem para a minimização desses riscos caberia certamente às empresas, seja por meio dos EPCS ou de EPIs mais adequados, seja implementando um processo de gerenciamento dos riscos em que os trabalhadores pudessem participar ativamente da sua concepção e implementação, sendo sujeitos e não apenas objetos das ações de segurança e saúde no trabalho.

Por outro lado, caberia uma intervenção do poder público junto à população, no tocante ao acondicionamento do lixo, como separar e identificar claramente os materiais infectantes, perfurantes e cortantes do lixo comum, isso porque o ciclo do lixo está apenas começando quando ocorre o descarte. Depois disso, seu recolhimento depende de outros atores sociais que dão vida a um mundo de trabalho indispensável, cuja segurança e atenção deveriam constituir uma prioridade. Na Alemanha, país que mais recicla no mundo, por exemplo, desde 1972 existe a obrigatoriedade para os cidadãos de descartar o lixo em sacolas de cores diferentes (Deutsche Welle Brasil, 2017). Ao lado disso, é indispensável a ação do poder público junto às empresas (com ações de Vigilância em Saúde do Trabalhador e fiscalizações do Ministério Público do Trabalho), assim como a criação de políticas públicas voltadas para a saúde e segurança dos coletores de lixo domiciliar. 
Embora recorrendo a estratégias defensivas para eufemizar a percepção dos riscos no trabalho, a partir de iniciativas individuais, e especialmente coletivas, os trabalhadores sabem que elas têm uma eficácia limitada, que a qualquer momento, frente a uma situação de acidente, por exemplo, elas podem não ser eficazes e expor os trabalhadores a uma situação de fragilidade ainda maior. Essa situação exige empenho por parte da empresa no sentido de mapear em profundidade os riscos na busca de tecnologias mais apropriadas para contê-los. Por outro lado, essas iniciativas devem se conjugar a melhorias nas condições de trabalho, especialmente no tocante a remuneração, suporte médio-odontológico-hospitalar, formação profissional, entre outras, que contribuam para tirar da invisibilidade essa categoria profissional tão importante para a sociedade.

$\mathrm{O}$ apelo à defesa se apresenta como um caminho natural para trabalhadores que se veem constantemente diante dos riscos e do perigo. Todavia, é preciso atentar para que esse uso não favoreça a acomodação, a naturalização e a transformação do que é nocivo à saúde em algo cotidiano e imutável. É também preciso mitigar o percurso que parece longo para que exista reconhecimento social, capaz de dar maior visibilidade e valorização à atividade de coleta de lixo e aos coletores.

Como vimos, os trabalhadores, apesar dos problemas que enfrentam, procuram de maneiras diversas se proteger, evitar o adoecimento, o acidente, não obstante sejam conscientes de que esses esforços estejam em desequilíbrio com o volume e a variedade dos riscos. Em função disso, podem tornar-se grandes parceiros na promoção da saúde e segurança no trabalho, se a vontade dos outros atores sociais, especialmente a empresa, se mostrar efetiva.

\section{Referências}

Anjos, L. A., \& Ferreira, J. A. (2000). A avaliação da carga fisiológica de trabalho na legislação brasileira deve ser revista! O caso da coleta de lixo domiciliar no Rio de janeiro. Cadernos de Saúde Pública, 16(3), 785-790. doi: 10.1590/ S0102-311X2000000300026

Araújo, A. J. S. (2001). Paradoxos da modernizaçäo: terceirizaçäo e segurança em uma refinaria de petróleo (Tese de Doutorado). Rio de Janeiro: FIOCRUZ.

Dejours, C. (1992). A loucura do trabalho: Estudo de psicopatologia do trabalho. (5’a ed.). (A. I. Paraguay e L. L. Ferreira, trads.). São Paulo: Cortez-Oboré.

Dejours, C. (2011). Da psicopatologia á psicodinâmica do trabalho. In Lancman, S., Sznelwar, L. I. (Orgs). Christophe Dejours: da psicopatologia à psicodinâmica do trabalho. (3a ed.). (F. Soudant, trad.) (pp. 57-123). Brasília: Paralelo 15.

Dejours, C. (2012). Trabalho vivo (F. Soudant, trad.). Brasília: Paralelo 15.

Dejours, C. (2017). Psicodinâmica do Trabalho: Casos Clínicos. Porto Alegre: Dublinense.

Dejours, C., \& Gernet I. (2012). Psychopathologie du travail. Issy-les-Moulineaux Editeur: Elsevier Mason.

Dejours, C., Abdoucheli, E., \& Jayet, C. (2011). Psicodinâmica do trabalho: contribuições da escola dejouriana à análise da relação prazer, sofrimento $e$ trabalho. (M. I. S. Betiol, coord. e trad) São Paulo: Atlas.

Deutsche Welle Brasil. (2017). Alemanices: As regras do lixo. In: Deutsche Welle - Made for minds. Bonn: Deutsche Welle. Recuperado em 31 de agosto, 2018, de https://www.dw.com/pt-br/alemanices-as-regras-do-lixo/a-38708393.

Dias A. G., Diniz A. C., Antonio. L. S., Matos R. F., Braga D. L. C., \& Magossi A. (2015). Riscos Ocupacionais em Atividade de Coleta de Resíduos Sólidos. E \& S - Engineeringand Science, 1(3), 3-17.

Dos Santos, Z. (2007). Segurança no trabalho e no meio ambiente. Rio Grande do Sul: Instituto de Física da Universidade Federal do Rio Grande do Sul. Disponível em: http://www.if.ufrgs.br/ Acesso em: 01 nov. 2017.

Echternacht, E. H. O., \& Castro, M. G. L. (2017). Precariedade e gestão de acidentes de trabalho: a terceirização no setor elétrico. Ação Ergonômica, 12(1), 91-98.

Flaig, R. (2004). Perda auditiva induzida por ruído em motoristas de caminhão de lixo urbano. Dissertação (Mestrado em Engenharia de Produção). Florianópolis: Universidade Federal de Santa Catarina.

Laville, C., \& Dionne, J. (1999). A construção do saber: Manual de metodologia da pesquisa em ciências humanas. Porto Alegre: Ed. UFMG/ArtMed,
Lazzari, M. A., \& Reis, C, B. (2011). Os coletores de lixo no município de Dourados (MS) e sua percepção sobre os riscos biológicos em seu processo de trabalho. Ciência \& Saúde Coletiva, 16(8), 3437-3442. doi: 10.1590/ S1413-81232011000900011

Mendes, A. M. (2007). Da psicodinâmica à psicopatologia do trabalho. In A. M. Mendes (Ed.), Psicodinâmica do trabalho: Teoria, método e pesquisas (pp. 2348). São Paulo, SP: Casa do Psicólogo.

Ministério da Saúde. (2006). Perda auditiva induzida por ruído (Pair). Brasília: Editora do Ministério da Saúde.

Ministério do Trabalho. (2018). Classificação Brasileira de Ocupações - 5142: Trabalhadores nos serviços de coleta de resíduos, de limpeza e conservação de áreas públicas. Brasília: Ministério do Trabalho. Recuperado em 27 de agosto, 2018, de http://www.mtecbo.gov.br/cbosite/pages/pesquisas/ BuscaPorTituloResultado.jsf

Molinier, P. (2013). Trabalho e psique: Uma introdução à psicodinâmica do trabaIho (F. Soudant, trans.). Brasília: Paralelo 15.

Nouroddine, A. (2004). Risco e atividade humana: Acerca da possível positividade aí presente. In M. Figueiredo, M. Athayde, J. Brito, \& D. Alvarez (Orgs.), Labirintos do trabalho: Interrogações e olhares sobre o trabalho vivo (pp. 37-62). Rio de Janeiro: DP \& A.

Oliveira, F. G. (2016). Do trabalho sujo à bela obra: o que é triar materiais recicláveis?: Um estudo em Psicossociologia do Trabalho (Tese de Doutorado). em Psicologia). Belo Horizonte: Universidade Federal de Minas Gerais.

Pedrosa, F. P., Gomes, A. A., Mafra, A. S. Albuquerque, E. Z. R. \& Pelentir, M. G. S. A. (2010) Segurança do trabalho dos profissionais da coleta de lixo na cidade de Boa Vista - RR. In XXX Encontro Nacional de Engenharia de Produção, São Carlos. Anais do XXX ENEGEP 2010 - Maturidade e desafios da Engenharia de Produção: competitividade das empresas, condições de trabalho e meio ambiente. Rio de Janeiro: Editora da ABEPRO.

Pinho, L. M., \& Neves, E. B., (2010). Acidentes de trabalho em uma empresa de coleta de lixo urbano. Caderno de Saúde Coletiva. 18(2), 243-251.

Porto, M. F. P. (2000). Análise de riscos nos locais de trabalho: Conhecer para transformar. Cadernos de saúde do trabalhador (pp. 5-41). São Paulo: Instituto Nacional de Saúde do Trabalhador.

Rouquayrol, M. Z., \& Goldbaum, M. (1999). Epidemiologia, história natural e prevenção de doenças ( 5 a ed). Rio de Janeiro: MEDSI.

Santos, Z. (2007). Segurança no trabalho e no meio ambiente. Rio Grande do Sul: Instituto de Física da Universidade Federal do Rio Grande do Sul. Disponível em: http://www.if.ufrgs.br/ mittmann/NR-9_BLOG.pdf>. Acesso em: 01 nov. 2017

Santos, I. V. A. (2008). Estudo dos riscos de acidentes de trabalho em coletores de lixo. Em ANAP - Associação amigos da natureza da Alta Paulista (Org.), Trabalhos completos do IV Fórum Ambiental da Alta Paulista [CD]. São Paulo: ANAP.

Santos, M. C. O., Lima, F. P. A., Murta, E. P., \& Motta, G. M. V. (2009). Desregulamentação do trabalho e desregulação da atividade: o caso da terceirização da limpeza urbana e o trabalho dos garis. Production, 19(1), 202-213.doi: 10.1590/S0103-65132009000100013

Seligmann-Silva. (2010). Acidentes de trabalho e a dimensão psíquica. Fórum do Trabalhador, São Paulo: Abril. Disponível em: https://pt.scribd.com/ document/236733793/Acidentes-de-Trabalho-e-a-Dimensao-Psiquica

Seligmann-Silva, E. (2011). Trabalho e desgaste mental: O direito de ser dono de si mesmo. São Paulo: Cortez.

Silva, N. M., \& Muniz, H. P. (2011). Vivências de trabalhadores em contexto de precarização: um estudo de caso em serviço de emergência de hospital universitário. Estudos e Pesquisas em Psicologia, 11(3), 821-840.

Smidt, L. H. \& Vendruscolo, G. B. B.(2006). Exposição doscoletores de lixo domiciliar a riscos ambientais de um município da região das Missões/RS. Trabalho apresentado no fórum internacional integrado de cidadania, Universidade Regional Integrada do Alto Uruguai e Missões - Campus Santo Ângelo/RS.

Souza, D. O. (2009). A sistematização da assistência de enfermagem(SAE) aos profissionais da coleta de lixo urbano. Trabalho apresentado no 610 congresso brasileiro de enfermagem, Fortaleza.

Stiglitz, J. (2002). A Globalização e seus malefícios. A promessa não cumprida de benefícios globais. São Paulo: Futura.

Vasconcelos, R. C., Lima, F. P. A., Camarotto, J. A., Abreu, A. C. M. S., \& Coutinho Filho, A. O. S. (2008). Aspectos da complexidade do trabalho de coletores de lixo domiciliar: a gestão da variabilidade do trabalho na rua. Gestão \& Produção, 15(2), 407-419. doi: 10.1590/S0104-530X2008000200015

Vasconcellos, J. G. O. (2002). Coronelismo nas organizações: a gênese da gerência autoritária brasileira. In Davel, E.; Vasconcellos, J. G. (Eds.). "Recursos" humanos e subjetividade. Petrópolis: Vozes. 
Velloso, M. P., Santos, E. M., \& Anjos, L. A. (1997). Processo de trabalho e acidentes de trabalho em coletores de lixo domiciliar na cidade do Rio de Janeiro. Cadernos de Saúde Pública, Rio de Janeiro, 13(4), 693 -700. 